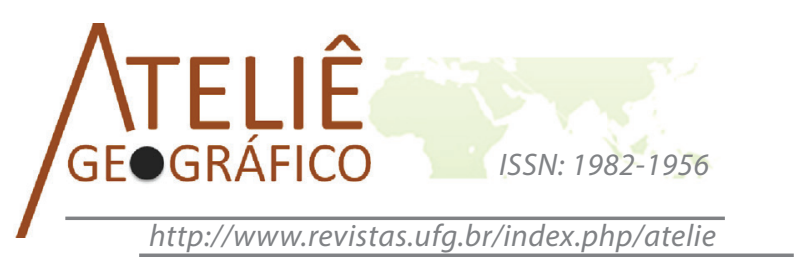

\title{
O letramento cartográfico nos anos iniciais do Ensino Fundamental
}

\section{The cartographic literacy in the Elementary School}

\section{El alfabetización cartográfica años la Eseñanza Inicial Obligatoria}

\author{
Carla Costa de Morais \\ Universidade de São Paulo \\ carlamorais@usp.br
}

Andrea Coelho Lastória

Universidade de São Paulo lastoria@ffclrp.usp.br

\author{
Filomena Elaine Paiva Assolini \\ Universidade de São Paulo \\ elainefdoc@ffclrp.usp.br
}

\begin{abstract}
Resumo
Neste artigo apresentamos os resultados de uma pesquisa de mestrado concluída. Buscamos compreender as concepções e práticas docentes sobre letramento cartográfico de cinco professoras dos anos iniciais, inseridas na rede municipal de ensino de Ribeirão Preto-SP. Focalizamosas estratégias de ensino, os conteúdos, as dificuldades com a linguagem cartográfica, bem como, as concepções docentessobre o letramento cartográfico. A legitimação teórica foi construída a partir de autores da Cartografia Escolar, na definição dos saberes docentes e na discussão sobre a formação inicial e continuada. A pesquisa é caracterizada como um estudo de caso de natureza qualitativa.Os dados foram coletados por meio de entrevistas, análise documental e observação das práticas. Pretendemos ampliar as questões de ensino-aprendizagem da linguagem cartográfica para além das questões formativas: trazendo à tona a necessidade de se discutir currículo e políticas públicas dos cursos de formação de professores.
\end{abstract}

Palavras-chave: Cartografia escolar; Letramento cartográfico; Práticas pedagógicas. 


\begin{abstract}
In this article we show the results of an investigation in master level that has been completed. The issue addressed is the understanding of teachers' conceptions about the cartographic literacy of five teachers in the early years that are entered in the municipal schools of Ribeirão Preto-SP. We intend to show the use of the term cartographic literacy rather literacy to indicate to literacy teaching practices and reading wider world. We also try to find in the teaching practices the strategies, the content worked and the difficulties that the teachers face with the Cartographic language. This work is featured as a case study of a qualitative nature. Data were collected through interviews, document analysis and observation of practices. We intent to broaden the issues of teaching and learning of cartographic language beyond the formative issues: bringing to the fore the need to discuss public policy curriculum and training courses for teachers.
\end{abstract}

Keywords:School cartography, Mapping literacy, Pedagogical practices.

\begin{abstract}
Resumen
En este artículo se muestran los resultados de una investigación en el nivel de maestría que ha sido completado. El tema abordado es la comprensión de las concepciones de los profesores sobre la alfabetización cartográfica de cinco maestros en los primeros años que estén inscritos en las escuelas municipales de Ribeirão Preto-SP. Se pretende mostrar el uso del término alfabetización cartográfica en lugar de alfabetización para indicar a las prácticas de alfabetización y la lectura de un mundo más amplio. También tratamos de encontrar en las prácticas de enseñanza de las estrategias, el contenido trabajaban y las dificultades que enfrentan los maestros con el lenguaje cartográfico. Este trabajo se presenta como un caso de estudio de naturaleza cualitativa. Los datos fueron recolectados a través de entrevistas, análisis de documentos y observación de las prácticas. Tenemos la intención de ampliar los temas de enseñanza y aprendizaje del lenguaje cartográfico más allá de las cuestiones formativas: haciendo hincapié en la necesidad de discutir los cursos del plan de estudios y de formación de política pública para los profesores.

Palabras clave: cartografía escolar, alfabetización Cartografía, prácticas pedagógicas.
\end{abstract}

\title{
Introdução
}

Apoiados na literatura disponível sobre a didática da Geografia e da Cartografia, encontramos poucos estudos sobre os saberes de professores e o ensino de conteúdos das didáticas específicas, como a Geografia e a Cartografia Escolar que se ensinam na escola.Notamos ser consenso entre os pesquisadores brasileiros e internacionais da área de Cartografia Escolar que ensinar o mapa para as crianças e compreender o seu processo de ensino e aprendizagem são desafios permanentes para os professores da escola fundamental (Lesann, 2009; Almeida, 2007; Lastória e Fernandes, 2013; Cazetta, 2009; Castellar, 2011, dentre outros). Dessa forma, pensamos que realizar pesquisas sobre as concepções docentes e como as professoras organizam seu trabalho de ensinar por meio da linguagem cartográfica na escola é de fundamental importância para compreendermos o processo de aquisição dessa linguagem. Diversos investigadores apontam a pesquisa 
sobre ensino e aprendizagem da linguagem cartográfica na escola como relevante para a melhoria da educação geográfica (Martinelli, 2001; Straforini, 2004; Callai, 2005; Simielli, 2007;Lastória, Moraes e Fernandes, 2013, dentre outros).

Considerando a literatura escassa sobre pesquisas de concepções docentes e as práticas de ensino envolvendo a linguagem cartográfica, estamos convencidos da necessidade de investigações que enfoquem a compreensão do cotidiano escolar, dos saberes e do trabalho docente com a Cartografia Escolar,visto que o domínio da linguagem cartográfica é fundamental para aprender Geografia na escola.

A partir do exposto, buscamos na pesquisa intitulada "Cartografia Escolar nos Anos Iniciais: o letramento cartográfico nas práticas das professoras" investigar as concepções e práticas docentes relacionadas ao letramento cartográfico ${ }^{1}$ que professoras dos anos iniciais da rede municipal de Ribeirão Preto - SP possuem. Para trabalhar o letramento cartográfico com os alunos, é necessário, em primeiro lugar, que o professor detenha esse conhecimento e as pesquisas de Simielli (2007) e Lessan (2009) indicam que essa não é realidade dos professores dos anos iniciais no Brasil. Entendemos que a investigação das concepções e práticas docentes possibilita compreender aspectos relevantes dessa temática a fim de buscarmos caminhos possíveis para uma real efetivação desse ensino.

Por se tratar de uma investigação na interface das áreas de Educação, de Geografia e de Cartografia Escolar elegemos o professor como importante ator no cenário de nossa pesquisa. Trazemos trechos das entrevistas e dos registros das práticas observadas com o intuito de problematizar o ensino da linguagem cartográfica nos Anos Iniciais.

\section{Metodologia}

Optamos pela abordagem qualitativa da pesquisa educacional. Neste percurso, entendemos que mais relevante do que se definir pela abordagem qualitativa ou quantitativa, é justificar sua escolha e ajustar o método utilizado para que seja adequado ao objeto da pesquisa. As obras de Brandão (2007), Fonseca (1999), Mazzotti (2011) trazem aspectos dessa perspectiva. Concordamos que em uma investigação científica o processo metodológico é "artesanal" e varia de acordo com o objeto de pesquisa e seu contexto (ROMANELLI, 1998; AZANHA, 1992). Definimos, então, nossa pesquisa como sendo um estudo de caso do tipo avaliativo. Este, segundo André (2005), ocorre quando um ou mais casos são estudados para fornecer informações a quem toma decisões ou apresentar um panorama sobre uma realidade pouco observada. Utilizamos de entrevistas com roteiro semiestruturado, observação de práticas envolvendo a linguagem cartográfica e de análise documental para obtenção dos dados. O processo foi submetido e aprovado por um comitê de ética em pesquisa. Durante o período de observação recolhemos documentos do contexto escolar que nos ajudaram a elucidar

1. Entendemos o letramento cartográfico como o processo de aquisição da linguagem cartográfica, de seus elementos, simbologia e significação. Tfouni (1994) traz a perspectiva de letramento como processo mais amplo à alfabetização baseada na Análise de Discurso presente na teoria Sócio-Histórica de Letramento de Matriz Francesa. 
vários aspectos da investigação, principalmente quando relacionamos os dados obtidos em tais documentos com as informações das entrevistas e do registro das práticas. Dentre os documentos, foram objeto de nossa análise o Planejamento Anual dos Conteúdos, o diário de classe (como registros de todo o conteúdo ministrado nas aulas, o qual permitiu conhecer a sequência didática do que já foi ensinado sobre nosso tema), o Parâmetro Curricular Nacional - PCN de História e Geografia para os anos iniciais e as Diretrizes de Ensino da Rede Municipal de Ribeirão Preto - SP.

O objetivo principal da pesquisa foi compreender quais as concepções sobre o letramento cartográfico as professoras da Rede Municipal de Ribeirão Preto - SP possuem. No processo de investigação da questão de pesquisa definimos três objetivos específicos. A saber:1. Discutir as concepções de letramento cartográfico que a literatura especializada da área apresenta; 2. Levantar as definições verbalizadas pelas professoras dos anos iniciais sobre o letramento cartográfico; 3. Descrever e analisar as práticas escolares identificadas pelas professoras como relacionadas ao letramento cartográfico.

\section{A cartografia escolar nos Anos Iniciais}

Do ponto de vista da aquisição de conhecimentos, o principal objetivo dos Anos Iniciais do Ensino Fundamental é trabalhar com habilidades que visam o domínio de competências básicas para dar início à construção dos conceitos estruturantes de qualquer disciplina, sendo a Geografia uma delas. Nesse nível de ensino, o professor não é especialista em uma única disciplina específica, mas a formação que recebeu deve qualificá-lo para trabalhar com as noções básicas com vistas ao aprendizado de todas as áreas do conhecimento.

Concordamos com Biddle (1978) quando afirma que todos precisam aprimorar sua percepção do espaço já que vivem e desenvolvem suas atividades nele. Lesann (2009), Martinelli (2001) e Almeida e Oliveira (2000), dentre outros, explicitam que a construção de bases conceituais para a Geografia inicia-se nos Anos Iniciais do Ensino Fundamental pela tomada de consciência dos elementos do espaço próximo, comuns aos alunos, ou seja, a sala de aula, a escola, o bairro da escola, dentre outros. A partir desses estudos, autores como Carlos (1996), Callai (2003), Straforini (2004), dentre outros, criticam o estudo do lugar que se apresenta de forma linear e que se amplia gradativamente, sem que haja um constante ir e vir, com outros lugares. Sobre esta linearidade denominada por "círculos concêntricos" Callai (2005, p.230) afirma o seguinte:

A superação dessa lógica de que a criança aprende por níveis hierarquizados no caso do espaço, por níveis espaciais que vão se ampliando sucessivamente - requer o estabelecimento, pelo menos, de uma clareza de termos. Não estamos considerando que o estudo do meio é inócuo e desligado da realidade. Pelo contrário, ele pode constituir uma interessante possibilidade de ensino e aprendizagem. O que se está questionando é uma postura teórica que dá a referência, a forma de encaminhamento, postura que considera um espaço fragmentado e circular, o qual se amplia sucessivamente. Partindo do "eu", da família, cria-se uma proposição antropocêntrica - ou melhor, egocêntrica - ao redor do "eu". O problema não é partir do "eu", mas sim fragmentar os espaços 
que se sucedem e que passam a ser considerados isoladamente, como se tudo se explicasse naquele e por aquele lugar mesmo. A dinâmica do mundo é dada por outros fatores. E o desafio é compreender o "eu" no mundo, considerando a sua complexidade atual. (...) A referência teórica é buscada tanto na Geografia - a qual considera que o espaço é socialmente construído pelo trabalho e pelas formas de vida dos homens - como na Pedagogia - a qual considera que a aprendizagem é social e acontece na interlocução dos sujeitos (estejam eles presentes fisicamente, ocupando um espaço próximo, estejam eles distantes, mantendo contatos virtuais, ou sob a hegemonia de determinada condução política, econômica).

Não só interagir com o lugar, reconhecer suas peculiaridades através do contato corporal, mas como afirma Carlos (1996) é imprescindível comparar, constantemente, as diferenças entre os locais, para que os alunos compreendam que as diferenças geram, muitas vezes, mudanças nos espaços geográficos, que por sua vez, explicam diferenças étnicas, culturais, econômicas, etc.

Compartilhamos com Callai (2005, p.228) que "a leitura de mundo é fundamental para que todos nós que vivemos em sociedade possamos exercitar nossa cidadania". As últimas décadas possibilitaram outro olhar ao processo de alfabetização dos brasileiros. Saber somente escrever o próprio nome não mais significa exercer o direito de ser cidadão atuante e participativo na sociedade. É neste contexto que o ensinar Geografia nos Anos Iniciais torna-se essencial para formação crítica do educando, no qual o conceito de letramento cartográfico é defendido como o caminho para a posterior compreensão do espaço e suas relações.

$\mathrm{O}$ ensino de Geografia nos primeiros anos do Ensino Fundamental deve se preocupar em possibilitar a leitura de mundo, a partir da análise da realidade vivida e percebida pelo educando. Uma prática pedagógica que valoriza essa forma de aprendizagem proporciona a ampliação de habilidades e competências no educando para atuação no mundo social. Nessa perspectiva, torna-se essencial pensar em uma iniciação cartográfica, ou seja, pensar o educando envolvido com os conceitos e habilidades geográficas desde o início de sua escolarização.

Segundo Callai (2003, p. 57-58) ao iniciar o processo de a aquisição da leitura e da escrita em uma abordagem sócio histórica de letramento, o educador dos Anos Iniciais precisa estar atento para que o educando perceba que a Geografia não é:

uma coisa alheia, distante, desligada da realidade. Não pode ser um amontoado de assuntos, ou lugares (partes do espaço), onde os temas são soltos, sempre defasados ou de difícil (e muitas vezes inacessível) compreensão dos alunos. Não pode ser feita apenas de descrição dos lugares distantes ou de fragmentos do espaço.

Neste sentido, Cavalcanti (2004,p.33) acrescenta que:

É claro que o ensino de nenhuma matéria pode se pautar apenas pela memorização. Ensino é processo de conhecimento, é mudança de qualidade no 
pensamento e a memorização enquanto tal não é conhecimento, nem provoca mudança na qualidade do pensamento.

Diante do exposto, Lastória e Fernandes (2012) criticam tanto as práticas escolares que contemplam a Cartografia apenas como um apêndice dos conteúdos específicos quanto os livros didáticos que trazem seu conteúdo de forma fragmentada e desconectada dos outros capítulos.

A Cartografia permite ler e interpretar o espaço próximo ou distante através de símbolos que se relacionam entre si, representando no papel um espaço reduzido, que fornece ao leitor informações que o ajudarão a se localizar no espaço e a compreender os diferentes espaços do mundo e suas dimensões. Esta temática deve ser trabalhada já nos Anos Iniciais do ensino fundamental, através de jogos e brincadeiras (Martinelli, 1998).

Os conhecimentos cartográficos devem ser adquiridos em um processo de alfabetização, o qual Simielli (1986) também nomeia por "alfabetização cartográfica".

A alfabetização cartográfica, de acordo com Smielli (1986), deveria ser o objetivo básico dos Anos Iniciais. A autora propõe atividades que desenvolvam as seguintes noções: pontos, linha, área, lateralidade, orientação, localização, referências, noção de espaço e tempo.

Nesse contexto, conceitos geográficos como espaço, território, paisagem e lugar são norteadores no processo de um letramento cartográfico, já que possibilitam ao educando articular procedimentos e atitudes sobre o espaço e seu entorno.

Sobre este mesmo aspecto, salientamos a seguir as considerações de Pires (1997, p.73):

A alfabetização cartográfica não se refere apenas às atividades ligadas ao ensino da Geografia, mas, sim, a um processo interdisciplinar, incluindo aí a linguagem, a matemática, as ciências naturais e a arte. Trabalhando a linguagem cartográfica e a construção de cartograma, o aluno desenvolve o raciocínio lógico-matemático, as noções de espaço, a produção escrita e a compreensão de representações entre outros objetivos propostos pelas diferentes áreas do Núcleo Comum.

As pesquisas sobre Cartografia Escolar nos Anos Iniciais são pouco numerosas no Brasil. Apesar da produção ter aumentado nas últimas décadas, ainda é preciso investigar "o que" os professores entendem sobre o letramento cartográfico e "se" e "como" as noções cartográficas são trabalhadas nas práticas docentes dos Anos Iniciais das escolas públicas paulistas.

Conforme resultado de pesquisa (Romano, 2007) observamos que a disciplina de Cartografia não faz parte da matriz curricular de muitos cursos de formação inicial de professores. A disciplina justifica-se pelas lacunas e dificuldades na compreensão da linguagem cartográfica. Tal dificuldade é nítida tanto para os alunos das escolas, quanto para os professores. De acordo com Castellar (2011) é preciso que os professores compreendam os fundamentos teóricos da discussão cartográfica, por isso a Cartografia merece relevância no currículo escolar. Os conteúdos precisam ser tratados na formação 
(inicial e continuada) dos professores, na medida em que, para ensiná-los, é necessário se apropriar deles.

Explica-nos Simielli (2007) que na década de noventa algumas pesquisas se voltaram para os Anos Iniciais do ensino fundamental, e seu principal enfoque era na análise do processo de aquisição dos elementos da linguagem gráfica. A autora investigou como os professores trabalhavam as informações referentes à "alfabetização cartográfica" e constatou, em várias cidades do país, a leitura ineficiente de mapas pelos próprios professores das escolas. Tal aspecto evidencia um problema real relacionado à ausência ou insuficiência do processo de "alfabetização cartográfica" tanto na escolaridade formal e nos programas de formação inicial e continuada de professores. A referida autora pesquisou, também, como os professores trabalhavam as informações relativas à "alfabetização cartográfica" e o resultado de sua pesquisa é alarmante. A saber: apenas $12,5 \%$ de um total de 1.219 professores pesquisados conseguiram trabalhar com a referência de orientação geográfica adequadamente.

Somam-se a estes fatores as políticas públicas de avaliação que não valorizam as áreas de História e Geografia. A atual política de ensino do Governo do Estado de São Paulo, implementada em 2008 pela Secretaria Estadual de Educação, apresenta materiais didáticos que contemplam apenas as áreas de Língua Portuguesa e Matemática para os Anos Iniciais do ensino fundamental. Na organização curricular veiculada, a Geografia (assim como a História) "pode" ser trabalhada por meio de textos ou projetos interdisciplinares. Existe supervisão para garantir que os professores cumpram os conteúdos curriculares implementados e, também, existe avaliação periódica dos alunos, da escola e, consequentemente, dos próprios professores.

No cenário nacional temos a Prova Brasil que pontua e classifica a qualidade do ensino dos municípios e suas escolas por (entre outras variáveis) uma avaliação geral de conhecimentos da Língua Portuguesa e Matemática. No âmbito municipal, temos anualmente a Avaliação Interna da Rede, elaborada pela Secretaria Municipal de Educação de Ribeirão Preto - SP. Esta também se baseia nas duas avaliações já citadas anteriormente, ou seja, também não prioriza a área de Geografia (nem a Cartografia Escolar), dentre outras. Vivemos, portanto, um período de complexos fatores externos a sala de aula, referentes às políticas públicas e curriculares que influenciam diretamente a prática de ensino dos professores e a vida cotidiana dos alunos.

De acordo com os Parâmetros Curriculares (BRASIL, 1997) o período que corresponde aos Anos Iniciais do ensino fundamental $\left(1^{\circ}\right.$ ao $5^{\circ}$ ano) é prioritário para a efetivação da "alfabetização cartográfica" ou, como preferimos denominar,"letramento cartográfico". Na faixa etária dos seis aos onze anos, a construção cognitiva das noções espaciais (de acordo com as teorias piagetianas sobre o desenvolvimento infantil) quando estimuladas, são melhores desenvolvidas para, depois serem aperfeiçoadas nos Anos Finais do ensino fundamental e médio. De acordo com Castellar (2011), as noções elementares do letramento cartográfico (como a de proporção, por exemplo) podem ser exploradas desde a Educação Infantil. Diante do exposto destacamos que 
o uso da linguagem cartográfica nos anos iniciais contribui para a construção da cidadania do aluno, pois permitirá a ele compreender os conteúdos e conceitos geográficos por meio de uma linguagem que traduzirá as observações abstratas em representações da realidade mais concretas. (Castellar, 2011, p.121).

$\mathrm{O}$ professor possui papel fundamental no processo de ensino-aprendizagem ao organizar práticas significativas que garantam a aquisição efetiva da linguagem cartográfica pelo educando. Por meio da leitura de autores que dedicam seus estudos às práticas escolares, aos saberes e à formação docente, trazemos alguns dos saberes docentes que envolvem o processo de ensino dos conteúdos, bem como buscamos destacar a formação inicial e continuada como relevantes na construção das práticas pedagógicas.

De acordo com Oliveira (2003) o saber docente é um dos elementos constitutivos do conhecimento escolar, caracterizado por um conjunto de conhecimentos, informações, valores, normas, condutas, técnicas e estratégias que subsidiam e efetivam a prática do professor. Nessa lógica, o conhecimento docente é proveniente de diversas instâncias: da formação inicial e continuada, das diversas formas de organização da comunidade, da família, da vida social, da prática profissional. Para Tardif, Lessard e Lahaye (1991) os saberes podem ser classificados em: saberes das disciplinas, saberes curriculares, saberes profissionais e saberes da experiência. Sendo os saberes profissionais e das disciplinas oriundos das instituições e dos cursos que trabalham com a formação do professor, enquanto os saberes da experiência são provenientes da prática na sala de aula. Os saberes curriculares são originados dos objetivos, métodos, conteúdos e discursos adotados pela escola. Por serem provenientes da prática cotidiana, os saberes da experiência passam a ser incorporados pelo professor na sua vivência individual e coletiva, tomam forma de habitus e costumam ser caracterizados como habilidades adquiridas através do "saber fazer" e do "saber ser". Souza (2000) afirma que os saberes da experiência não provêm do currículo, de instituições formadoras bem como não são sistematizados por teorias porque são parte constituinte da prática docente e, como tal, representam a cultura docente em ação.

Buscamos no livro Formação Continuada de Professores: processos formativos e investigativos, de Assolini e Lastória (2010), uma entrevista com Selma Garrido Pimenta. Nesta, a professora explica a formação inicial e continuada de professores a partir do conceito de profissionalização da carreira docente. Para Pimenta apud Assolini e Lastória (2010) não é possível que o professor adquira todos os conhecimentos necessários para a atividade docente de uma só vez (na formação inicial). A formação continuada ganha destaque nas pesquisas recentes e "quebra" a visão de formação tecnicista que já vinha sendo desconstruída em meados das décadas de 1980 e 1990. Em contraposição à formação tecnicista, Veiga (2002) defende a formação de docentes como agentes sociais, além de ser a favor da discussão política que contempla (desde a formação inicial e continuada) as condições de trabalho, de salário, de carreira e de organização da categoria. 
Referenciados pelo contexto acima citado e de acordo com os autores que se dedicam ao ensino da Cartografia e à formação de professores passemos a comentar alguns dos resultados obtidos com a análise dos dados da nossa pesquisa.

\section{Resultados e discussão}

Após levantar aspectos sobre os processos formativos das professoras e analisar suas práticas pedagógicas pudemos verificar que elas carregam consigo conhecimentos e concepções de uma Geografia e Cartografia Escolar Tradicionais, construídos ao longo de sua experiência escolar como estudante.

De acordo com a professora 1:

Eu fiz em três anos e não tive a disciplina de metodologia para cada área, só uma geral. Eu tive Sociologia, Filosofia, Didática. No magistério, fiz de primeira a quarta série e eu tinha até um caderninho separado onde eles ensinavam o conteúdo de Ciências, História e Geografia junto, eu tenho até meus cadernos, mas como faz muito tempo não dá pra utilizar muita coisa, é antigo. Eu não tive base de Geografia. Eu planejo, eu leio o texto ou trago alguma coisa, eu busco muita coisa. (Professora 1).

De modo geral, observamos a consulta em sites, materiais de colegas e experiência pessoal como as referências efetivamente utilizadas nas aulas que abordavam a Cartografia. A formação docente inicial e continuada foi considerada, pelas próprias professoras, insuficiente para que elas sintam segurança no trabalho com a Linguagem Cartográfica. Verificamos que algumas cursaram algum componente curricular que envolvia a Geografia e a Cartografia Escolar, outras não tiveram tal formação na graduação em Pedagogia. As atividades realizadas nesses referidos componentes curriculares, segundo as próprias professoras, não contribuíram para aproximá-las adequadamente da ciência cartográfica e de seu ensino. As professoras investigadas não tiveram oportunidade de entender o processo de letramento cartográfico a ser realizado desde os Anos Iniciais. Dessa forma, elas reconhecem a importância da formação continuada em Geografia, apesar de não receberem, em nenhum momento, como docentes da rede em que atuam.

Outro aspecto recorrente desvelado nas análises é a priorização do ensino para a alfabetização na Língua Materna e a preparação para as operações Matemáticas básicas. As professoras lecionam muitos conteúdos de Língua Portuguesa e Matemática, pois o seu trabalho é avaliado pelo desempenho através de provas dessas áreas do conhecimento. As políticas públicas educacionais, seja na esfera nacional ou municipal, reforçam tal comportamento pela adoção de avaliações externas que não contemplam a Geografia e a Cartografia nos seus parâmetros avaliativos. Lastória e Fernandes (2012 p.2) reforçam a importância do saber geográfico e cartográfico serem melhor difundidos na comunidade acadêmica, escolar e entre aqueles que elaboram as políticas públicas educacionais. Segundo as autoras:

A falta de clareza a respeito da importância dos saberes geográficos no desenvolvimento do chamado "raciocínio espacial" também é um dos 
responsáveis pela fragilidade da formação de professores. Não se ensina a raciocinar o espaço, pois nem sempre o professor reconhece o próprio conceito de espaço e suas principais categorias (ou recortes) que nos ajudam a entendêlo. Estamos nos referindo a paisagem, ao território, a região e ao lugar.

Segundo Castellar e Vilhena (2010), a Cartografia ainda é entendida por muitos como uma técnica e não como uma linguagem. Castellar (2011) também esclarece que é a partir do trabalho nos Anos Iniciais, com a linguagem cartográfica, que o aluno poderá construir observações mais abstratas e representações da realidade, mas sempre a partir da realidade concreta. Assim, muitos equívocos são cometidos por docentes que, por não compreenderem a própria linguagem cartográfica, não a ensinam, dificultando a aprendizagem dos alunos.

Ficou claro pela investigação que o letramento cartográfico não é um processo bem compreendido pelas cinco professoras que afirmaram não terem sido formadas para ensiná-lo nos anos iniciais. Sob a ótica das professoras, a Cartografia está relacionada, exclusivamente, ao ensino de Geografia e este (assim como o ensino de História e Ciências) é pouco valorizado e priorizado nos Anos Iniciais.

Direcionando as entrevistas para o objeto da pesquisa perguntamos se as professoras já haviam recebido formação continuada na área da Geografia, especificamente da Cartografia. Nenhuma das entrevistadas já havia frequentado cursos na área de Geografia/Cartografia nos anos iniciais. Conforme as falas a seguir:

Não. Eu tive no magistério oficinas, mas na formação continuada nunca. É sempre em Português e Matemática o carro chefe da Educação. E mesmo a questão da faculdade, do vestibular pesa para cobrarem só isso. E também tem um problema, você não tem tempo hábil pra isso. Se você der as cinco áreas do conhecimento você vai dar cinco aulas mal dadas porque as crianças estão vindo sem formação básica. (Professora. 2)

A concepção da professora de que as áreas de Português e Matemática são "o carro chefe da Educação" advém de anos de docência convivendo com cursos de formação continuada e avaliações externas que priorizam apenas essas áreas disciplinares. A falta de aprofundamento em outras áreas do conhecimento escolar faz com que a professora reproduza o discurso de priorizar determinadas noções e conteúdos em detrimento de outros, como se estas últimas não contemplassem objetivos e meios comuns que possibilitam o pleno desenvolvimento da criança.

A professora 2 explicita ainda a concepção de que para trabalhar com as áreas específicas do conhecimento, como a Geografia e a Cartografia Escolar, a criança precisa primeiro ser alfabetizada na língua materna. "Na prática os alunos precisam dominar a leitura e escrita antes e está cada vez mais difícil." (Professora 2).

Ao apontar que os alunos necessitam dominar a leitura e a escrita antes que seja trabalhado noções e conceitos cartográficos, a referida professora parece não reconhecer as possibilidades que o ensino da linguagem cartográfica traz para o letramento e registro escrito. Visto que apenas o trabalho com mapas já possibilita o contato com um diferente gênero textual, sua interpretação e o conhecimento de sua função social. A professora 
demonstra desconhecer as orientações dos Parâmetros Curriculares Nacionais de História e Geografia para os Anos Iniciais sobre a importância de se trabalhar o letramento cartográfico desde a Educação Infantil e não percebe que a criança já possui contato, muitas vezes anterior à escolarização, com a linguagem cartográfica ou simbólica. Outro aspecto a ser pontuado é o desconhecimento de propostas de trabalho interdisciplinares, visto que os mapas temáticos podem ser utilizados em conteúdos de diversas áreas do conhecimento.

Lastória e Fernandes (2012) reforçam a importância que vários pesquisadores vêm apontando sobre o ensino "de" mapas e não apenas "com" mapas nos Anos Iniciais. Na concepção de Geografia como ciência que se dedica à compreensão da produção do espaço, o mapa torna-se um recurso indispensável. As autoras reforçam a complexidade da linguagem cartográfica que, assim como as outras linguagens, exige pré-requisitos à sua compreensão sendo fundamental o ensino de elementos da Cartografia pelo mapa. Segundo Simielli (1986) antes de ler mapas o aluno necessita ter contato com atividades que desenvolvam as noções de ponto, linha, área, lateralidade, orientação, localização, referências, noção de espaço e tempo. Entendemos, portanto, que várias dessas noções precisam ser iniciadas desde os Anos Iniciais.

$\mathrm{Na}$ fala da professora 2 encontramos alguns dos critérios utilizados para a seleção de material didático e, também,elementos que indicam sua própria concepção sobreo ensino de Geografia (associado ao de História).

A cada três anos a gente participa (da escolha do livro didático). Nós pegamos o planejamento anual e a gente vai elencando todos os objetivos que a gente tem. Escolho um livro que tem a ver com a realidade do aluno, que fica mais próximo. Prefiro livro com muitas imagens, que chame a atenção deles porque História e Geografia é um assunto "chatérrimo" e se não tiver muita ilustração, figura, fica difícil pra eles. Procuro também nomes de autores conceituados. (Professora. 2)

Sobre material didático e suas relações com conteúdos cartográficos, explicitamos o trecho a seguir de outra professora investigada:

O livro deles eu acho chato, com linguagem cansativa, fica muito na imaginação. $\mathrm{Eu}$ acho que o visual para criança é muito importante, principalmente nessa área. Geralmente o que os livros trazem é bem pouco sobre orientação espacial. $\mathrm{O}$ material que a gente tem acesso a isso não contempla. Costumava pedir para os alunos fazerem um mapa, mas eu acho que é uma coisa automática, eles vão lá tiram um mapa e pronto. Eles não aprendem nada com isso. Eu não aprendi e acho que eles também não vão aprender, além de acharem uma chatice... os alunos têm muita dificuldade de se orientar no espaço. Eles confundem direita e esquerda, acham que São Paulo é um país. Inclusive teve uma prova de Matemática que eu dei e que eles deveriam seguir o caminho na malha quadriculada para a direita, esquerda, contar e foram poucos alunos que conseguiram fazer. (Professora 3)

A professora 3 menciona que copiava mapas enquanto era estudante. Provavelmente ela não aprendeu a ler corretamente um mapa e muito menos a construir 
um. Estamos de acordo com Lastória e Fernandes (2013) ao afirmarem que muitos professores dos anos iniciais possuem dificuldades em desenvolver práticas pedagógicas com a linguagem cartográfica porque não foram e nem são formadas para isso, ou seja, não sabem ensinar noções relacionadas ao espaço, sejam elas "com mapas" ou "sobre mapas".

Notamos, entretanto, pelas análises que realizamos das práticas docentes em sala de aula, que as professoras trabalharam a Geografia, mais especificamente, a Cartografia Escolar. Elas buscaram desenvolver práticasque motivassem seus alunos tendo em vista que consideram a Geografia uma disciplina "chata/ chatérrima" de ser aprendida. Recursos audiovisuais, jogos, atividades com maquetes, mapas e globo terrestre foram adotados como parte das estratégias das professoras para trabalhar com a linguagem cartográfica, embora alguns equívocos tenham sido registrados no desvelar das práticas.

\section{Considerações finais}

Reconhecemos as dificuldades variadas que as professoras enfrentam cotidianamente e o reflexo delas em sua prática pedagógica. Sugerimos, portanto, que sejam realizadas mais investigações com intuito de trazer novos esclarecimentos e melhores explicações sobre as concepções docentes e as políticas públicas curriculares voltadas ao ensino da Geografia e da Cartografia Escolar, além de trabalhos que contemplem a formação inicial e continuada dos professores.

Considerando a importância dessa perspectiva, salientamos que não se trata de responsabilizar o professor pelas ações praticadas, conforme apontado por Pimenta (2010) existe limites de natureza política, que envolvem desqualificação do corpo docente e ausência de ações efetivas de investimento no desenvolvimento profissional dos professores.

Nesta investigação, levamos em consideração, também, os limites da formação básica e continuada das professoras. Sobre a primeira, trata-se de um processo inicial que não deveria ser visto como final ou único no processo de desenvolvimento docente. Sobre a segunda, é preciso salientar a fragilidade dos programas de formação continuada que não priorizam todas as áreas dos conhecimentos escolares, nem possibilitam suas integrações. Identificar tais limites permite, sob nossa ótica, que encontremos formas de superá-los.

Neste cenário, a educadora, continua a buscar (muitas vezes solitária) alternativas e formas complementares de aprimorar sua prática e ampliar seus estudos sobre o fazer docente. Por isso, entendemos a necessidade da formação continuada como complementação necessária para auxiliar na aquisição de noções e conteúdos específicos que sua formação inicial não abrangeu.

A Cartografia Escolar precisa ser ressignificada nos Anos Iniciais do ensino fundamental. Para tanto, a realização de estudos do tipo diagnóstico, que valorizem os saberes dos professores, suas concepções a respeito do letramento cartográfico e das práticas escolares são necessários. Entendemos que realizar uma pesquisa nas interfaces das áreas de Educação, Geografia e Cartografia não é tarefa simples, porém acreditamos 
que o estudo de caso realizado com docentes de escolas da rede municipal de Ribeirão Preto-SP é significativo, pois nos ajuda a elucidar um contexto pouco conhecido pelos professores e pelos próprios pesquisadores da área educacional.

\section{Referências}

ALMEIDA, R. D. (org.). Cartografia Escolar. São Paulo: Contexto, 2007.

ALMEIDA, R. D. \& OLIVEIRA, A. R. O estudo da localidade através de atividades com mapas municipais no ensino de geografia. Ciência Geográfica, Bauru, vol. II, n. 16, p. 71-74, 2000.

ANDRÉ, M. E. D. A. Estudo de Caso em Pesquisa e avaliação educacional. Brasília: Liber Livro Editora, 2005.

ASSOLINI, F. E. P.; LASTORIA, A. C. (Orgs.)Formação continuada de professores: processos formativos e investigativos. Ribeirão Preto - SP: Compacta, 2010.

AZANHA, J.M.P. Uma ideia de pesquisa educacional. São Paulo: EDUSP, 1992.

BRANDÃO, Z. Entre questionários e entrevistas. In NOGUEIRA, M. A. et al. (orgs.) Familia \& Escola: trajetórias de escolarização em camadas médias e populares, Petrópolis, RJ, Vozes, 2007.

BIDDLE, Don. Abordagem conceitual do ensino da geografia na escola secundária. AGETEO, Rio Claro, 1978, texto n.2.

BRASIL. Secretaria de Educação Fundamental. Parâmetros curriculares nacionais: História e Geografia $1^{\circ}$ e $2^{\circ}$ ciclos. Brasília: MEC/SEF, 1997.

CALLAI, A. H. O ensino de Geografia: Recortes espaciais para análise. IN: Geografia em Sala de Aula: Práticas e Reflexões. Porto Alegre: Editora da UFRGS/Associação dos Geógrafos Brasileiros - Seção Porto Alegre, 2003, pg 57 - 63.

CALLAI, A. H. Aprendendo a ler o mundo: a geografia nos anos iniciais do ensino fundamental.Cad. Cedes, Campinas, v. 25, n. 66, p. 227-247, maio/ago. 2005.

CARLOS, Ana Fani. “O Lugar no/do Mundo”. São Paulo, Editora Hucitec, 1996.

CASTELLAR, S. V. A cartografia e a construção do conhecimento em contexto escolar. In: ALMEIDA, R. D. (org.) Novos rumos da cartografia escolar: currículo, linguagem e tecnologia. São Paulo: Contexto, 2011.

CASTELlAR, S.; VILHENA, J. Ensino de Geografia. Coleção ideias em ação. São Paulo: Cengage Learning, 2010.

CAVALCANTI, L. S. Geografia, escola e construção de conhecimentos. 6. ed. Campinas, São Paulo: Papirus, 2004. 192p.

CAZETTA V. Aproximações e distanciamentos entre a linguagem cartográfica e outras linguagens. Biblio 3W. Revista Bibliográfica de Geografía y Ciencias Sociales, Universidad de Barcelona, Vol. XIV, $\mathrm{n}^{\circ}$ 847, 15 de noviembre de 2009. <http://www. ub.es/geocrit/b3w-847.htm>. [ISSN 1138-9796]. 
FONSECA C. Quando cada caso Não é um caso: pesquisa etnográfica e educação. Revista Brasileira de Educação. 1999; n.10: pp.58-78.

LASTÓRIA, A. C. Didática da Geografia e Geografia Escolar. In: FONSECA; S.G. (org.)Ensino Fundamental: conteúdos, metodologias e práticas. Campinas: línea, 2009, v. 1, pp. 295-312.

LASTÓRIA, A. C.; FERNANDES, S.A.S. de. A Geografia e a linguagem cartográfica: de nada adianta saber ler um mapa se não se sabe aonde quer chegar. Ensino em Revista (UFU. Impresso), v. 19, pp. 323-334, 2012.

LASTÓRIA, A. C.; FERNANDES, S.A.S. de. Cartografia escolar na formação inicial de professores dos anos iniciais do ensino fundamental: ficção ou realidade?. In: PORTUGAL; J.;OLIVEIRA, T.; Pereira; T. (orgs.) (Geo)grafias e linguagens: concepções, pesquisas e experiências formativas. Curitiba-PR: CRV, 2013, p. 53-68.

LASTÓRIA, A.C., MORAES, L. B. de.; FERNANDES, S. A. S. de. Diálogos sobre a Geografia Escolar e linguagem cartográfica. In: ASSOLINI, F. E. P.; LASTÓRIA, A. L. (orgs.) Diferentes linguagens no contexto escolar: questões conceituais e apontamentos metodológicos. Florianópolis-SC: Insular, 2013, pp. 107 - 117.

LESANN, J. Geografia no ensino fundamental I, Belo Horizonte-MG: Argvmentvm, 2009.

MARTINELLI, M. Gráficos e mapas: construa-os você mesmo. São Paulo, Moderna, 1998.

MARTINELLI, M. As representações gráficas da Geografia: os mapas temáticos, 2001. Tese (Livre-docência). FFCLH, USP, São Paulo.

MAZZOTTI, A.J. Impacto da pesquisa educacional sobre as práticas escolares. In ZAGO, Nadir et al. (org.)Itinerários de pesquisa: perspectivas em sociologia da educação, Rio de Janeiro: Lamparina, 2011.

OLIVEIRA, A. R. A cartografia escolar e as práticas docentes nas séries iniciais do ensino fundamental. (dissertação), São Carlos: UFSCar, 2003.

PIMENTA, S. G. Saberes pedagógicos e atividade docente. 3. ed. São Paulo: Cortez, 2010.

PIRES JÚNIOR, R. Alfabetização Cartográfica: Algumas considerações sobre o uso do mapa nas séries iniciais do Primeiro Grau. In: Revista de Geografia. UERS, n.1, jan. 1997, p.73-38.

ROMANELLI, G. A entrevista Antropológica: Troca e Alteridade. In: ROMANELLI, G.; BIASOLI-ALVES, Z. M. M. (orgs.) Diálogos metodológicos sobre prática de pesquisa. Ribeirão Preto-SP: Legis Summa, 1998, pp. 119-132.

ROMANO, S. M. M. Alfabetização cartográfica: a construção do conceito de visão vertical e a formação de professores. In: CASTELLAR, S (org.). Educação Geográfica: teorias e práticas docentes. 2. ed. São Paulo: Contexto, 2007.

SIMIELLI, M. H. O mapa como meio de comunicação cartográfica: Implicações no ensino de geografia do $1^{\circ}$ grau. São Paulo: FFCLH/USP, 1986. 
SIMIELLI, M. H. O mapa como meio de comunicação e a alfabetização cartográfica. In: ALMEIDA, R. D. (org.) Cartografia Escolar. São Paulo: Contexto, 2007.

SOUZA, V. C.A prática docente de professores leigos de geografia: estudo de caso. 2000. Dissertação (Mestrado em Educação). FE, UFMG, Belo Horizonte.

STRAFORINI, R. Ensinar Geografia: o desafio da totalidade - mundo nas séries iniciais. São Paulo: Annablume, 2004.

TARDIF, M.; LESSARD, C. e LAHAYE, L.. Os professores face ao saber - esboço de uma problemática do saber docente.Teoria e Educação. Porto Alegre, n.4, pp215- 234, 1991.

TFOUNI, L. V. Perspectivas históricas e ahistóricas do letramento. Cadernos de Estudos Lingüísticos - 26, 1994, p. 49-62.

VEIGA, I.P. A. (Org) Projeto político-pedagógico da escola: uma construção possível. 14 ed, São Paulo: Papirus, 2002.

Carla Costa de Morais

Mestre em Educação pela Universidade de São Paulo - USP.

Professora na Instituição de Ensino Infantil e Fundamental Liceu Albert Sabin

Rua Edmo Bernardes de Mello, 161 - CEP 14096-490- Ribeirânia - Ribeirão

Preto-SP

carlamorais87@yahoo.com.br

\section{Andrea Coelho Lastória}

Doutora em Educação pela Universidade Federal de São Carlos e docente do Departamento de Educação e Comunicação da Faculdade de Filosofia, Ciências e Letras de Ribeirão. USP - Faculdade de Filosofia, Ciências e Letras de Ribeirão Preto

Av. Bandeirantes, 3900 - CEP 14040-901 - Bairro Monte Alegre - Ribeirão Preto - SP -Brasil

lastoria@ffclrp.usp.br

\section{Filomena Elaine Paiva Assolini}

Doutora em Educação pela Universidade Federal de São Carlos e docente do Departamento de Educação e Comunicação da Faculdade de Filosofia, Ciências e Letras de Ribeirão. USP - Faculdade de Filosofia, Ciências e Letras de Ribeirão Preto

Av. Bandeirantes, 3900 - CEP 14040-901 - Bairro Monte Alegre - Ribeirão Preto - SP -Brasil elainefdoc@ffclrp.usp.br 